\title{
A Study on Health, Social and Economic Problems of Elderly Population in An Urban Setting Kerala
}

\author{
Authors \\ Dr Mini S S $\mathbf{1}^{1}$, Dr Anuja $\mathbf{U}^{2}$ \\ ${ }^{1}$ Associate Professor, Department of Community Medicine, Government Medical College, Kollam Kerala \\ ${ }^{2}$ Associate Professor, Department of Community medicine Government Medical College \\ Thiruvananthapuram Kerala, India \\ Corresponding Author \\ Dr Mini S S \\ Associate Professor, Department of Community Medicine, Government Medical College, Kollam Kerala
}

\begin{abstract}
Background: The present study was conducted to estimate the health, social and economic problems of elderly population in an urban setting in Kerala and also the utilization of primary health care services by them.

Methods: This study was done as a cross sectional study in an urban population. 152 people aged above 60 years was selected from the community using two stage cluster sampling technique. Data was collected using a structured pretested questionnaire by one to one interview technique. Data entry was done in SPSS version 15 and the results were expressed in percentages

Results: Regarding the health problems $35.5 \%$ was having acute health problems for the last one month. About chronic problems $81 \%$ was having any one chronic problems and on treatment. $72 \%$ is having more than one chronic problem. The self reported economic problems are, $42.2 \%$ having a monthly income below 1000 rupees but $69 \%$ said their income is inadequate to meet their expenses and $50 \%$ is depending on family members for their expenses. The main social problems identified are abuse by the family members ( $32 \%$.) quarrel with Family members and neighbours (27\%).

Conclusions: The estimated acute and chronic morbidities and the social and economic problems are high among the elderly population and it is very relevant in a state like Kerala having the largest share o elderly population among the Indian states.

Keywords: Health problems, economic problems, social problems, utilization of primary health care services by elderly.
\end{abstract}

\section{Introduction}

Ageing is a natural process that begins at birth and progress throughout one's life and ends at death. The world population is rapidly ageing. The UN defines a country as ageing when the proportion of people above 60 reaches $7 \%$. But currently in India $8 . \%$ of population are elderly and it is expected that this will reach $19 \%$ in $2050^{1}$. The increasing proportion of elderly people in the population puts welfare and health care systems as well as families under pressure .Many people living longer with chronic diseases put additional strain. The Government of India adopted National policy on older people in January 1999 to reaffirm the 
commitment to ensure the well being of older persons Kerala has maximum proportion of elderly people in its population. $12.6 \%$ of population is above 60 years of age ${ }^{2}$. Kerala also got the highest life expectancy at birth among all the Indian states. Because of the advanced stage of demographic transition, the share of elderly 1 population is higher in Kerala. The large elderly population coupled with higher prevalence of chronic illness among them contributing high burden of morbidities among them Along with all these factors the society norms and family structure in Kerala are changing and the elderly are suffering due to the impact of this changing social scenario.

In this back ground a study was under taken to estimate the health, social and economic problems among the elderly people and also the primary health care utilization by these people.

\section{Objectives}

1. To study the health, social and economic problems among the elderly population in an urban setting.

2. To study the primary health care service utilization by this elderly population.

\section{Methods}

\section{Study design}

This study was done as a community based cross sectional study to estimate the prevalence of health, social and economic problems of elderly population.

\section{Study setting and study subjects}

The study was conducted from 1stuly to August 31 st 2015 at field practicing area of Pangappara PHC, which is the urban health training centre attached to the Community medicine department of government medical college Thiruvananthapuram. Study subjects were all persons above 60 years of age and who are residing in the area for more than one year.

\section{Sample size}

Sample size was fixed according to a study done by Rakesh Kumar and Mohammed Shafee ${ }^{3}$ in Tamil Nadu, nearby state to Kerala, they got a prevalence of any one chronic morbidity among the elderly population a $65.2 \%$. so keeping the prevalence as
$65 \%$ and allowable error $12 \%$ of the prevalence (7.80) the sample size calculated as 149 and it was decided to study 150 people .

\section{Sampling technique}

A total of 152 participants were recruited from the field practice area of Govt Medical College Thiruvananthapuram by multi stage cluster sampling technique. Two wards were selected randomly and from each ward three Anganwadi area were identified by random technique. From each selected anganwadi area, 25 eligible participants were recruited for the study in consecutive manner.

\section{Ethical consideration}

Informed consent was translated into the regional language Malayalam and a written informed cosent was obtained from all the participants after explaining the purpose of research .Institutional ethical committee approval was obtained from Government Medical college Thiruvananthapuram

\section{Data collection}

Information was collected from the participants using the pre-tested interview schedule through one to one interview technique .

Definition of main study variables

1. Socio Demographic Variables as Age, Marital Status, Educational Status, Occupation stated by the patient .

2. Acute health problems - Any health problem needed treatment from a doctor or a health facility as outpatient or inpatient during last one month.

3. Chronic health problems- Any diagnosed health problem for which the person is on condinous treatment.

4. Social and economic problems-Self reported by the participants

\section{Data analysis}

The data entry and analysis were done using statistical package for social sciences (SPSS) version 15. The results were expressed in percentages 
Table 1 Age distribution of study population

\begin{tabular}{|l|c|c|}
\hline Age & Number & Percentage \\
\hline $60-64$ & 63 & 41.4 \\
\hline $65-69$ & 36 & 23.7 \\
\hline $70-74$ & 21 & 13.8 \\
\hline$>75$ & 32 & 21.1 \\
\hline Total & 152 & 100 \\
\hline
\end{tabular}

$41.4 \%$ of study population is in the age group 60to 64 and $23.7 \%$ is between 65 to $6913.8 \%$ between 70 to 74 and $21.1 \%$ above the age of 75 years

\section{Health problems of elderly population}

Table 2 a Acute Health problems of study population

\begin{tabular}{|l|c|c|}
\hline Health problems & Number & Percentage \\
\hline Any acute health problems & 54 & 35.5 \\
\hline Types of acute problems (N=54 ) & & \\
\hline Fever & 22 & 40.7 \\
\hline A RI & 22 & 40.7 \\
\hline Injury & 5 & 9.2 \\
\hline Diarrhoea & 1 & 1.8 \\
\hline Others(UTI etc ) & 4 & 7.4 \\
\hline
\end{tabular}

Table 2 b Chronic health problems of elderly population

\begin{tabular}{|l|c|c|}
\hline Chronic health problems & no & percentage \\
\hline Any one chronic health problems & 122 & 80.2 \\
\hline More than one chronic problem & 109 & 71.7 \\
\hline Hypertension & 83 & 54.5 \\
\hline Diabetes & 55 & 36.2 \\
\hline Arthritis & 55 & 36.2 \\
\hline Cataract & 23 & 35.1 \\
\hline CAD & 19 & 12.5 \\
\hline Renal diseases & 8 & 5.3 \\
\hline Others & 23 & 15.1 \\
\hline
\end{tabular}

Table $1 \mathrm{a}$ and $\mathrm{b}$ showing the acute and chronic problems of the elderly population. About the acute health problems $35.5 \%$ got any one acute health problems for the last one month that need treatment from a health facility or a doctor. Among this acute health problems Fever and Acute respiratory illness were the most common ailments reported by the elderly.

About the chronic health problems $80.2 \%$ was having any one chronic health problems but $71.7 \%$ was having more than one chronic health problem. Among the chronic health problems hypertension was most common problem among the elderly $54.5 \%$ was having hypertension. The second important chronic problems reported were diabetes and arthritis $36.2 \%$ respectively. The other chronic problems reported were Catract Coronary artery disease and renal problems and they were $35.5 \%$. $12.5 \%$ and $5.3 \%$ respectively.

\section{Socoal problems of elderly poipulation}

Table 3 a Social problem reported by the study subjects

\begin{tabular}{|l|c|c|}
\hline Self reported problem & Number & $\%$ \\
\hline Attending social function & 129 & 84.8 \\
\hline Not meeting family members and friends & 85 & 55.9 \\
\hline Self reported abuse from family members & 38 & 25 \\
\hline Quarrel with family members \& neighbours & 55 & 36.1 \\
\hline Time for watching TV & 100 & 65.7 \\
\hline Right to choose the TV programmes & 48 & 31.5 \\
\hline Spending free time alone & 11 & 7.2 \\
\hline Time for reading books & 8 & 5.2 \\
\hline
\end{tabular}

Table 3 b Care takers of elderly population

\begin{tabular}{|l|c|c|}
\hline Care taker & no & percentage \\
\hline Daughter/sun & 122 & 80.3 \\
\hline Relative/Home nurse & 6 & 8.9 \\
\hline None & 24 & 15.8 \\
\hline Satisfied with the care taker & 128 & 84.2 \\
\hline
\end{tabular}

Table 3c Habits among elderly population

\begin{tabular}{|l|c|c|}
\hline Habits & No & Percentage \\
\hline Smoking & 24 & 15.8 \\
\hline Alcoholism & 25 & 16.4 \\
\hline Pan chewing & 23 & 15.1 \\
\hline Others & 4 & 2.6 \\
\hline
\end{tabular}

Regarding the social problems reported by the study population $84.8 \%$ of population is attending social functions but $55.9 \%$ said they are not meeting family members and friends. Other social issues reported are abuse from family members and some quarrel with family members and neighbours, $25 \%$ and $36.1 \%$ respectively. $65.7 \%$ said they get time to watch TV programes but only $31.5 \%$ got the right to choose the TV programme. $7.2 \%$ spending free time alone and only $5.2 \%$ spending time for reading. Regarding the care taker $80.3 \%$ look after by their daughter or sun but $15.8 \%$ not looked after by anyone. $84.2 \%$ is satisfied with the care takers.

The self reported habits by the study population are smoking, alcoholism, panchewing and some other habits like tobacco powder use etc are $15.8 \%$, $16.4 \%, 15.1 \%$ and $2.6 \%$ respectively . 
Self reported economic problems of elderly population

Table 4 Self reported economic problems by study population

\begin{tabular}{|l|c|c|}
\hline Economic problems & Number & Percentage \\
\hline Monthly income below Rs 1000 & 87 & 57.2 \\
\hline Source of income & 51 & 33.6 \\
\hline \multicolumn{1}{|c|}{ Employment } & 21 & 13.6 \\
\hline \multicolumn{1}{|c|}{ Focial pension } & 76 & 50 \\
\hline $\begin{array}{l}\text { Income members } \\
\text { expenses inadequate to meet the }\end{array}$ & 105 & 69.1 \\
\hline $\begin{array}{l}\text { Borrowed money for health care } \\
\text { expenditure }\end{array}$ & 40 & 26.3 \\
\hline $\begin{array}{l}\text { Sold earning like land/ornaments for } \\
\text { health care }\end{array}$ & 28 & 18.4 \\
\hline
\end{tabular}

The main economic problem reported by the elderly people was a low monthly income below Rs 1000 by $57.2 \%$ and $69.1 \%$ said the monthly income is inadequate for meet the expenses. The main source of income was from family members followed by employment $.33 \%$ of elderly are now also doing some work to earn money. social pension was source of income for $13.6 \%$ and $16.4 \%$ getting pension as the benefit for their government service . Economic problems due to health expenditures was about $26.3 \%$ have borrowed money for health care expenditure and $18.4 \%$ sold their earning for meeting the health care expenditure .

\section{Health care utilisation by the elderly people}

Table 5 Health care utilization by the study population

\begin{tabular}{|l|c|c|}
\hline Health care utilization & No & $\%$ \\
\hline Having regular health check up & 92 & 60.5 \\
\hline Utilizing PHC services & 44 & 28.9 \\
\hline Service from JPHN/ASHA worker & 16 & 10.5 \\
\hline Having health insurance & 22 & 14.5 \\
\hline $\begin{array}{l}\text { Utilizing any community based } \\
\text { palliative care services }\end{array}$ & 7 & 4.6 \\
\hline
\end{tabular}

Only $60.5 \%$ of elderly got regular health check up from any health care facility. Only $28.9 \%$ have utilized services from the PHC and $10.5 \%$ have received any care from the JPHN/ASHA worker. Only $14.5 \%$ got health insurance coverage and $4.6 \%$ is utilising the community based palliative care services an initiative by Government of Kerala.

\section{Discussion}

The study was a population based cross sectional study done using two stage cluster sampling method which ensures generalizability of the results to the study population. The present study high lights the health, social and economic problems of elderly population in an urban setting and their health seeking behaviour.

About the age distribution of the elderly population about $65,1 \%$ of population is between $60-69$ years of age. A study done by Madhu $\mathrm{T}$ et al in $2013^{4}$ in Kurnool they got $56.33 \%$ of population was between 60-69 age group in the urban area which is less than in our study. This can be due to the larger proportion of elderly among the Kerala population. Regarding the morbidity profile reported by the study population the overall chronic morbidity among them was about $80.2 \%$ and $71.7 \%$ was having more than one chronic morbidity .A studies done in other parts of India got some varying results compared to this. A study done in Karnataka by Shahul Hameed ${ }^{5}$

Etal got only $3.7 \%$ is having no morbidity and $25.3 \%$ got more than one morbidity. In both studies hypertension, impaired vision and arthritis were the important morbidities identified. But the diabetes prevalence was very less compared to Kerala. (19.7 and 36.2) Another outpatient based study done by DR Cynthia Subhaprada S at Andhra Pradesh ${ }^{6}$ the main morbidities present were hypertension (61.22) osteoarthritis (44.9\%) and among the acute problems Respiratory disease was most common ailment almost similar to our study.

The important social problems identified are low income an abuse from family members and quarrels and out of pocket expenditure for health care .But majority of the elders are taken care by the family members and $84.2 \%$ were satisfied with the care takers. Another important finding was the habits among the elderly population .Even though we are giving awareness about healthy ageing the habits 
still remains as important risk factors for various diseases.

Regarding the health seeking behaviour, in our study only $60.5 \%$ is having regular health checkups. The health seeking behaviour of elderly population depends on many factors mainly economic status. A study done in Kerala by Subrata Mukherjee et al ${ }^{7}$ based on population based survey it was found $t$ hat there is a significant difference between the health seeking behaviour of rich and poor elderly.

Only a very small percentage is using the palliative care services but in Kerala government is the major provider of palliative care ${ }^{8}$ The utilisation of PHC services by the population is also very poor only $28.9 \%$. About health insurance coverage only $14.5 \%$ got medical insurance. A study done by A Lena, K Ashok et al ${ }^{9}$ at Udupi Taluk Karnataka also got some similar finding that the elderly not aware of the services and the health care utilisation is only $14.6 \%$

\section{Conclusions}

The elderly in Kerala suffering from acute and chronic health problems along with economic and social problems. Kerala suggest that ageing of the population is going to impose severe challenges to the public health sector.

\section{Acknowledgement}

Department of community medicine Government medical college Thiruvananthapuram. Kerala India 2011 MBBS batch Government medical college Thiruvananthapuram Kerala India

\section{References}

1. Population Reference Bureau PRB www.prb.org/publication/reports/2012

2. Elderly in India 2016 Govt of India, Ministry of statistics and programe implementation. Central statistics office. Socoal statistics division www.mospi.gov.in

3. Rakesh Kumar and Mohammed Shafee Assessment of morbidity pattern and its correlates among elderly population in rural area of Perambalur Tamil Nadu India . ISSN
0976-9633 (online ) International Journal of biomedical research 2014

4. Madhu T,Sreedevi A A study of sociodemographic profile of geriatric population in the field practice area of Kurnool Medical college ISSN 2321-1431 International Journal of Research \& Development of Health April 2013 vol 1 (2)

5. ShahulHameed,Nanjesh Kumar ,Prashanth M naik, Sachdananda, Prasanna K S Morbidity pattern among the elderly population in rural area of Dakshina Kannada,Kaenataka-Across sectional study. OpenAccess article www.njcmindia .org National journal of community Medicine vol6 Issue 2 April June 2015

6. Dr,Cynthia Subhaprada S A cross sectional study on morbidity pattern among geriatric patients attending outpatient department of primary health centre Kurnool Andhra Pradesh International Jpurnal of current medical and applied sciences vol 6 Issue March 2015 pp 39-43

7. Subrata Mukerjee ,Jean Frederic Levesque Morbidity and outpatient care for elderly in Kerala ,South India Evidence from National population based survey. Journal of population Ageing September 2012 vol 5 Issue 3 pp 177-192

8. B Jayalekshmi, Suhita Chopra Chattergee Debolina Chattergee End of life charecteristics of the elderly An assessment of Home based palliative services in two Panchayats of Kerala Indian journal of Palliative care 2016 October -December 22 (4 ) 491-498

9. A Lena ,K Ashok ,M Padma, V Kamath ,A Kamath Health and social problems of elderly, A crosssectional study Udupi Taluk Karnataka Indian journal of community medicine 2009 volume 34 issue to page 131135 . 